\title{
Influence of Culture Media Formulated with Agroindustrial Wastes on the Antimicrobial Activity of Lactic Acid Bacteria
}

\author{
José R. Linares-Morales, Iván Salmerón-Ochoa, Blanca E. Rivera-Chavira, \\ Néstor Gutiérrez-Méndez, Samuel B. Pérez-Vega, and Guadalupe V. Nevárez-Moorillón*
}

Facultad de Ciencias Químicas, Universidad Autónoma de Chihuahua. Circuito Universitario s/n, Campus II. C.P: 31125 Chihuahua, Chih. México

\begin{abstract}
The discarding of wastes into the environment is a significant problem for many communities. Still, food waste can be used for lactic acid bacteria (LAB) growth. Here, we evaluated three growth media equivalent to de Mann Rogosa Sharpe (MRS), using apple bagasse, yeast waste, fish flour, forage oats, and cheese whey. Cell-free supernatants of eight LAB strains were tested for antimicrobial activity against nine indicator microorganisms. The supernatants were also evaluated for protein content, reducing sugars, $\mathrm{pH}$, and lactic acid concentration. Cell-free supernatants from fish flour broth (FFB) LAB growth were the most effective. The strain Leuconostoc mesenteroides PIM5 presented the best activity in all media. L. mesenteroides CAL14 completely inhibited L. monocytogenes and strongly inhibited Bacillus cereus (91.1\%). The strain L. mesenteroides PIM5 consumed more proteins $(\mathbf{7 7 . 4 2} \%)$ and reducing sugars $(56.08 \%)$ in FFB than in MRS broth $(51.78 \%$ and $30.58 \%$, respectively). Culture media formulated with agroindustrial wastes positively improved the antimicrobial activity of selected LAB, probably due to the production of antimicrobial peptides or bacteriocins.
\end{abstract}

Keywords: $L A B$, food waste residues, by-product, fermentation, antimicrobial, pathogens

Received: July 18, 2021 Accepted: October 18, 2021

First published online: October 20, 202

*Corresponding author Phone: +52-614-236-6000 ext. 4248

E-mail:vnevare@uach.mx

Supplementary data for this paper are available on-line only at http://jmb.or.kr.

pISSN 1017-7825 elSSN 1738-8872

Copyright $(92022$ by the authors. Licensee KMB. This article is an open access article distributed under the terms and condition of the Creative Commons Attribution (CC BY) license.

\section{Introduction}

It is well known that the manufacturing of many food products has led to the release of highly contaminated effluents into the environment, polluting soils and water bodies [1]. Fish production around the world for 2016 reached 171 million tons [2]; between 25 and 70\% become wastes polluting the environment if they are not converted into valuable products [3]. Beer industry effluent is another waste of importance. It contains a considerable amount of yeast waste that reaches about 19 million $\mathrm{kg}$ per year worldwide [4]. Likewise, a large amount of whey is discarded during dairy products manufacturing, which is a contaminant with a high biological and chemical oxygen demand [5-7]. In 2011, approximately 200 million tons of whey were produced worldwide [8]. Between 2011-2012, close to 12.2 million metric tons of apples were used for juice production [9]; nearly $35 \%$ of that fruit was discarded as bagasse [10].

The problems caused by food waste can be reduced if they are included in bioconversion processes to contribute to circular economy strategies [5]. Using agroindustrial wastes to produce bioactive compounds through microbial fermentation as substitutes for culture media ingredients would result in a low-cost, environmentally friendly process [7]. Therefore, fermentation with lactic acid bacteria (LAB) can be an excellent way to reuse those agroindustrial wastes. Although LAB strains are fastidious microorganisms that demand culture-rich media, with a high content of nitrogen, minerals, and vitamins, they have a proteolytic system that allows them to obtain the essential amino acids needed for their growth, enabling them to grow well in protein-rich food [4,7]. Peptone and yeast extract are expensive ingredients employed for the de Man, Rogosa, Sharpe culture medium (MRS) formulated for LAB's growth. Bustos et al. [11] and Sabo et al. [1] reported that only these ingredients account for almost $30 \%$ of MRS's total cost. However, these ingredients may be substituted by proteinaceous agroindustrial wastes, solving two of the most critical constraints for producing LAB metabolites for the food industry: ingredient availability and high cost $[12,13]$. LAB strains have shown improved antimicrobial activity in substrates such as fish wastes $[3,14]$, whey [15] and were also able to produce bioactive peptides from whey [16] and lactic acid [17].

LAB satisfactorily produced biomass, lactic acid, and bacteriocin when grown in a culture medium formulated with fish protein hydrolysates [3]. Also, LAB produced a fermented protein hydrolysate with antimicrobial 
activity, probably due to the production of antimicrobial peptides when fermenting fish wastes [14]. LAB improved their antimicrobial activity against several pathogen microorganisms when whey was employed as a substrate; however, antimicrobial substances were not determined [15]. In addition, proteolytic LAB strains could release bioactive peptides from whey proteins [16] and produce biomass and improve the recovery of lactose, proteins, and minerals from clarified, heat-treated milk whey [17].

Moreover, the use of brewer's yeast wastes has enhanced LAB activities, possibly due to cellular lysis at the culmination of their active phase, releasing soluble metabolites to the medium $[18,19]$. On the other hand, apple bagasse has been employed as a carbon source for lactic acid [18] and bacteriocin production [20] since it has a high content of soluble carbohydrates, which are crucial for biomass propagation $[10,20,21]$. Therefore, it is possible to consider using agroindustrial waste products to formulate alternative growth media for LAB growth. In a previous report [22], LAB isolated from vegetable sources were screened according to their proteolytic and antimicrobial activities by microtitration in MRS broth. Eight LAB strains ( 3 Enterococcus mundtii, 2 Enterococcus faecium, and 3 Leuconostoc mesenteroides) demonstrated the best antimicrobial activities against pathogenic microorganisms. Following the characterization of selected LAB strains, our objective in this research was to evaluate their antimicrobial activity compared to MRS broth when they were grown in three different culture media formulated with agroindustrial wastes as protein source.

\section{Materials and Methods \\ Microorganisms}

LAB, indicator microorganisms, and incubation conditions are listed in Table 1.

$\mathrm{LAB}$ isolated from vegetable sources were reported previously and selected based on their protease and antimicrobial activity against several indicator microorganisms [22].

\section{Characterization of Agro-Industrial Wastes}

The agroindustrial wastes employed were apple bagasse (AB) from Grupo La Norteñita (México), and yeast water waste (YW) from Tijarare Cervecería Artesanal (Mexico). Previously, YW was mixed with sterile water and allowed to decant for $30 \mathrm{~min}$. The darkest phase was separated, and the rest was taken as yeast water. Commercial fish flour (FF) was purchased at a local supermarket; cheese whey (CW) was donated by the Cheese Factory at the Animal Science Department, Universidad Autónoma de Chihuahua, and foraged oats, FO, (Avena sativa L. var. Karma) was obtained at Semillas Pura Sangre (Mexico). All agroindustrial wastes were analyzed to determine protein content and total nitrogen by the Kjeldahl method [23] and reducing sugars as glucose using the 3,5 dinitrosalicylic acid method [24].

\section{Culture Media Formulation}

Once the agroindustrial wastes were characterized, three culture media with similar proximal composition to MRS broth were formulated. Agroindustrial wastes were used as substitute ingredients in the equivalent amounts of carbon and nitrogen supplied in the MRS broth (Difco, USA), as reported by the company and indicated by the approximate amount of $\mathrm{C}$ and $\mathrm{N}$ supplied by peptone, yeast extract, and meat extract. To calculate the $\mathrm{C} / \mathrm{N}$ ratio, the $\mathrm{C}$ and $\mathrm{N}$ proportion provided by each component in the media formula was stoichiometrically calculated. Concentrations of Tween 80 and inorganic salts were maintained in equivalent amounts as in MRS broth. A culture medium base was prepared with $\mathrm{AB}$ and $\mathrm{YW}$ (substituting glucose and yeast extract, respectively) Tween 80 and inorganic salts. Later, three culture broths were prepared, each with a different protein source substituting for peptone and meat extract. The three media were fish flour broth (FFB), cheese whey broth (CWB), and forage

Table 1. Lactic acid bacteria and indicator microorganisms for the antimicrobial activity test.

\begin{tabular}{|c|c|c|c|}
\hline Group & Microorganism & Accession number/ATCC & Conditions \\
\hline \multirow[t]{9}{*}{ LAB } & Enterococcus mundtii ELO8 & MN636717 & $26^{\circ} \mathrm{C}, 24$ h Microaerophilic \\
\hline & Leuconostoc mesenteroides PIM5 & MN636704 & \\
\hline & Leuconostoc mesenteroides CAL14 & MN636705 & \\
\hline & Enterococcus faecium PIM4 & MN636718 & \\
\hline & Enterococcus mundtii JAV & MN636719 & \\
\hline & Enterococcus mundtii TOV9 & MN636706 & \\
\hline & Enterococcus faecium PEP11 & MN636707 & \\
\hline & Leuconostoc mesenteroides PEP12 & MN636720 & \\
\hline & Bacillus cereus & 11778 & \\
\hline \multirow[t]{3}{*}{ Gram + } & Listeria monocytogenes & 19114 & $37^{\circ} \mathrm{C}, 24 \mathrm{~h}$ \\
\hline & Staphylococcus aureus & 25923 & Aerobiosis \\
\hline & Aspergillus niger & $\mathrm{BUAP}^{*}$ collection & $26^{\circ} \mathrm{C}, 48 \mathrm{~h}$ \\
\hline \multirow[t]{3}{*}{ Molds } & Penicillium expansum & UDLAP $^{\star *}$ collection & Aerobiosis \\
\hline & Fusarium oxysporum & UDLAP $^{* *}$ collection & \\
\hline & Candida albicans & 10231 & $26^{\circ} \mathrm{C}, 24 \mathrm{~h}$ \\
\hline \multirow[t]{2}{*}{ Yeasts } & Saccharomyces cerevisiae & 9763 & Aerobiosis \\
\hline & Candida tropicalis & 1369 & \\
\hline
\end{tabular}

*BUAP: Benemérita Universidad Autónoma de Puebla. ${ }^{*}$ UDLAP: Universidad de las Américas Puebla. 
oats broth (FOB), formulated with commercial fish flour (FF), whey (CW) from the cheese industry, and forage oats $(\mathrm{FO})$ as the protein sources respectively.

\section{Fermentation of Culture Broths Formulated with Agroindustrial Wastes}

To determine the influence of the formulated media on the antimicrobial activity of the selected LAB isolates, MRS broth and the different media were inoculated with $5 \mathrm{ml}$ of an overnight growth of the LAB isolates tested. The broths were incubated at $26^{\circ} \mathrm{C}$ for $48 \mathrm{~h}$. Later, the supernatants were centrifuged at $3,800 \times g$ for $25 \mathrm{~min}$ ( $5810 \mathrm{R}$, Eppendorf, Germany) and pasteurized $\left(75^{\circ} \mathrm{C}, 3 \mathrm{~min}\right)$ to obtain the cell-free supernatants (CFS). LAB growth and preparation of the CFS were previously reported, while the methodology for evaluating the antimicrobial activity of the CFS of the LAB isolates also followed a previously reported method [22]. All experiments were carried out in triplicate.

To determine the influence of the formulated media on the antimicrobial activity of the selected LAB isolates, MRS broth and the different media were inoculated with the eight LAB isolates tested. A sample loop of each LAB strain was inoculated in tubes with $10 \mathrm{ml}$ of MRS broth. Later, $5 \mathrm{ml}$ of the overnight growth of each LAB strain was inoculated into $125 \mathrm{ml}$ Erlenmeyer flasks containing $45 \mathrm{ml}$ of each formulated media and MRS broth. The flasks were stationarily incubated at $26^{\circ} \mathrm{C}$ for $48 \mathrm{~h}$. Later, the supernatants were centrifuged at $3,800 \times g$ for $25 \mathrm{~min}$ (5810R, Eppendorf, Germany) and pasteurized $\left(75^{\circ} \mathrm{C}, 3 \mathrm{~min}\right)$ to obtain the cell-free supernatants (CFS). All experiments were carried out in triplicate.

\section{Antimicrobial Activity of the Cell-Free Supernatants}

Each CFS's antimicrobial activity was evaluated as the percentage of inhibition of the growth of indicator microorganisms following the microtiter method described by Linares-Morales et al. [22]. Briefly, $100 \mu \mathrm{l}$ of Brain Heart Infusion (BHI) broth for bacteria (Bioxon, México) and YM broth (yeast extract $3 \mathrm{~g} / \mathrm{l}$, malt extract $3 \mathrm{~g} / \mathrm{l}$, dextrose $10 \mathrm{~g} / \mathrm{l}$, peptone $5 \mathrm{~g} / \mathrm{l}$ ) for yeast and molds were transferred to a 96 -well microplate. To avoid the inhibitory effect of lactic acid produced by $\mathrm{LAB}$, broth media were supplemented with $\mathrm{K}_{2} \mathrm{HPO}_{4}(0.1 \mathrm{M})$. To each well, $30 \mu \mathrm{l}$ of indicator microorganism suspensions (Table 1 ) was added, with a concentration of $1.5 \times 10^{8} \mathrm{cells} / \mathrm{ml}$ for bacteria and yeast (0.5 McFarland standard) and $10^{3}-10^{4}$ mold spores (adjusted based on New Bauer chamber counts). Furthermore, $50 \mu \mathrm{l}$ triplicates of CFS previously was centrifuged at 3,800 $\times g$ for 25 min (5810R, Eppendorf, Germany) and pasteurized $\left(75^{\circ} \mathrm{C}, 3 \mathrm{~min}\right)$ were added. Lastly, $150 \mu \mathrm{l}$ of the supplemented media and $30 \mu \mathrm{l}$ of the microbial suspensions were incorporated as negative controls. The optical density at $595 \mathrm{~nm}\left(\mathrm{OD}_{0}\right)$ was determined with a microplate reader (Bio-Rad 550, Japan) as the initial lecture. Microplates were incubated following the conditions stated in Table 2 for each microorganism. When incubation finished, optical density $\left(\mathrm{OD}_{\mathrm{f}}\right)$ was obtained again, and the antimicrobial activity $(\mathrm{AA})$ was calculated employing the following equation:

$$
\mathrm{AA}=100-((\mathrm{DDO} / \mathrm{DDOc}) \times 100) .
$$

DDOs are the average difference between the samples' initial (OD0) and final (ODf) optical density. DDOc is the average of the difference $\left(\mathrm{OD}_{0}\right.$ and $\left.\mathrm{OD}_{\mathrm{f}}\right)$ of the optical density of the negative control. AA was classified as follows: higher than 50\% was considered strong inhibition, between 15 and $49.99 \%$ moderate inhibition, and lower than $14.99 \%$ was considered no inhibition. Indicator microorganisms were incubated in sterilized culture media formulated with agroindustrial wastes to determine whether the formulated media presented an antimicrobial effect.

\section{Chemical Analysis of Culture Broths and Cell-Free Supernatants from LAB Growth}

Consumption of proteins and sugars, $\mathrm{pH}$, and lactic acid production by the LAB strain with the best antimicrobial activity were determined. Thus, protein content by Bradford method [25], reducing sugars as fructose by the 3,5 dinitrosalicylic acid method [24], total titratable acidity (TTA) by the AOAC Official Method 942.15 [23], expressed as the amount in grams of lactic acid, and pH by the AOAC Official Method 981.12 [23], were determined for the CFS and the sterile broth and compared to the MRS broth.

\section{Statistical Analysis}

The effect of the culture media on the LAB's antimicrobial activity was subjected to an analysis of variance (ANOVA) followed by a Tukey simultaneous test for means differences. Statistical analyses were done using the Minitab 18 software (Minitab Inc., USA), with a significance level of $p<0.05$.

\section{Results}

\section{Culture Media Formulation}

Table 2 presents the reducing sugars, nitrogen, and proteins of the five agroindustrial wastes used to formulate the culture media for $\mathrm{LAB}$ growth. $\mathrm{AB}$ presented the highest content of reducing sugars (62.41\%), followed by $\mathrm{YW}$ (9.84\%) and FF (6.69\%). YW's nitrogen content (4.52\%) and FF (3.99\%) were higher than that of CW. Three culture media were formulated, considering the composition of the agroindustrial waste used, with equivalent amounts of the carbon provided by glucose and nitrogen provided by yeast extract, peptone, and meat extract present in the MRS broth; the composition of salts and the concentration of Tween 80 were maintained as in the MRS formulation (Table 3). The carbon/nitrogen ratios (C/N) of the three formulated culture media, FFB (3.55), FOB (3.43), and CWB (3.22), were lower than the $\mathrm{C} / \mathrm{N}$ ratio of the MRS broth (4.06). 
Table 2. Characterization in percentages of agro industrial wastes employed to formulate three culture media similar to MRS broth.

\begin{tabular}{lccccc}
\hline Variable & $\mathrm{AB}$ & $\mathrm{YW}$ & $\mathrm{FO}$ & $\mathrm{CW}$ & FF \\
\hline Red sugars & $62.41 \pm 0.06$ & $9.84 \pm 0.00$ & $2.49 \pm 0.01$ & $0.01 \pm 0.00$ & $6.69 \pm 0.02$ \\
Nitrogen & $0.66 \pm 0.21$ & $4.52 \pm 0.33$ & $1.7 \pm 0.03$ & $0.16 \pm 0.01$ & $3.99 \pm 0.11$ \\
Protein & $4.79 \pm 0.9$ & $28.25 \pm 2.07$ & $10.63 \pm 0.22$ & $1.02 \pm 0.32$ & $24.91 \pm 0.70$ \\
\hline
\end{tabular}

AB: Apple bagasse, YW: Yeast waste, FO: Forage oats CW: Cheese whey FF: Fish flour.

Table 3. Content in $\mathrm{g} / \mathrm{l}$ of MRS broth compared to three culture media formulated with agro industrial wastes as protein source.

\begin{tabular}{|c|c|c|c|c|c|c|}
\hline \multirow{2}{*}{ Ingredient } & \multicolumn{4}{|c|}{ Medium } & \multicolumn{2}{|c|}{ Nutrient } \\
\hline & MRS & FOB & CWB & FFB & Carbon & Nitrogen \\
\hline Yeast extract & 5 & & & & $\sim 0.5$ & $\sim 0.5$ \\
\hline Glucose & 20 & & & & 8 & 0 \\
\hline Peptone & 10 & & & & $\sim 3$ & $\sim 1.4$ \\
\hline Meat extract & 10 & & & & $\sim 3$ & $\sim 1$ \\
\hline Tween 80 & 1 & 1 & 1 & 1 & 0.59 & 0 \\
\hline Ammonium citrate & 2 & 2 & 2 & 2 & 0.64 & 0.99 \\
\hline Sodium acetate & 5 & 5 & 5 & 5 & 0.88 & 0 \\
\hline Magnesium sulphate & 0.2 & 0.2 & 0.2 & 0.2 & 0 & 0 \\
\hline Manganese sulphate & 0.05 & 0.05 & 0.05 & 0.05 & 0 & 0 \\
\hline Dipotassium phosphate & 2 & 2 & 2 & 2 & 0 & 0 \\
\hline Yeast water & & $11 \mathrm{ml}$ & $11 \mathrm{ml}$ & $11 \mathrm{ml}$ & 0.5 & 0.5 \\
\hline Apple bagasse & & 32.01 & 32.01 & 32.01 & 8 & 0.2 \\
\hline Forage oats & & 141 & & & 3.51 & 2.4 \\
\hline Cheese whey & & & $1000 \mathrm{~mL}$ & & 0.1 & 1.6 \\
\hline Fish flour & & & & 60 & 4 & 2.4 \\
\hline $\mathrm{C} / \mathrm{N}$ & 4.06 & 3.43 & 3.22 & 3.55 & & \\
\hline
\end{tabular}

FFB: Flour fish broth, FOB: Forage oats broth, CWB: Cheese whey broth.

\section{Antimicrobial Activity}

Fig. 1 shows the AA of LAB-CFS over indicator microorganisms compared among the formulated culture media and the MRS broth.

The FOB was the medium where the CFS from LAB showed less AA. Only L. mesenteroides PIM5 was able to inhibit the growth of more than two indicator microorganisms when cultured in FOB. The best antimicrobial activity was observed in the FFB where three LAB-CFS achieved strong inhibitions and three more achieved moderate inhibitions on all the yeasts evaluated. Moreover, four CFS of the LAB strains (L. mesenteroides PIM5 and CAL14, E. mundtii JAV15 and TOV9) could inhibit the growth of at least four indicator microorganisms when these LAB were grown in FFB. On the other hand, the second-best AA was observed in the MRS broth. Although four LAB-CFS achieved moderate inhibitions against at least four indicators, only three exerted strong inhibitions, and only one LAB-CFS moderately inhibited all the yeasts. Regarding the LAB strains, L. mesenteroides CAL14 completely inactivated or significantly reduced the growth of B. cereus, L. monocytogenes, and the yeasts assayed.

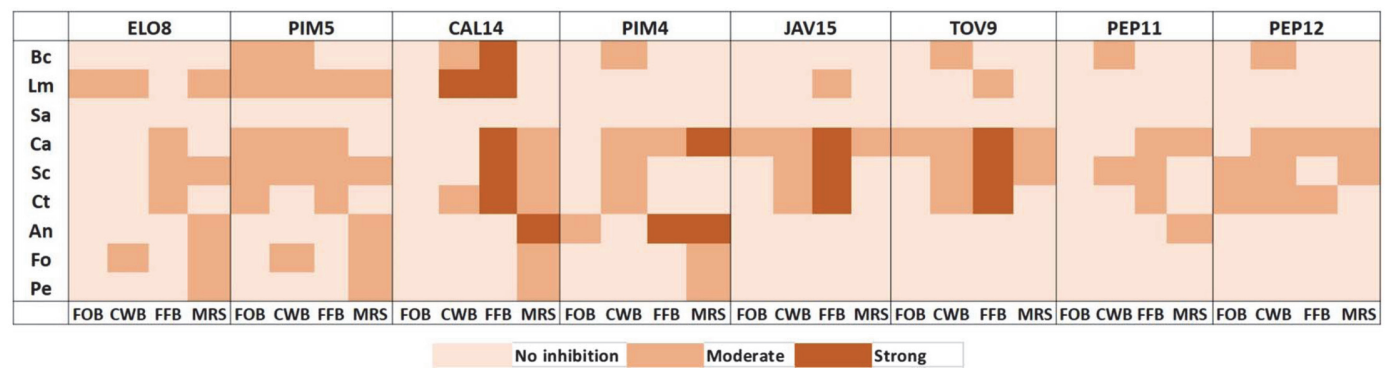

Fig. 1. Comparison of the antimicrobial activity of LAB-CFS against the indicator microorganisms per culture media. Strain of lactic acid bacteria: Enterococcus mundtii ELO8, Leuconostoc mesenteroides PIM5, Leuconostoc mesenteroides CAL14, Enterococcus faecium PIM4, Enterococcus mundtii JAV15, Enterococcus mundtii TOV9, Enterococcus faecium PEP11, Leuconostoc mesenteroides PEP12. Classification of antimicrobial activity: $>50 \%=$ strong inhibition; $15-50 \%=$ moderate inhibition; $<14.99 \%=$ no inhibition. Culture media: FOB: Forage oats broth, CWB: Cheese whey broth, FFB: Flour fish broth. Indicator microorganisms: Bc: B. cereus, Lm: L. monocytogenes, Sa: S. aureus, Ca: C. albicans, Sc: S. cerevisiae, Ct: C. tropicalis, An: A. niger, Fo: F. oxysporum, Pe: P. expansum. 
Table 4. Antimicrobial activities of sterile culture media formulated with agro industrial wastes and MRS broth against indicator microorganisms.

\begin{tabular}{lcccc}
\hline Indicator/Media & FFB & FOB & CWB & MRS \\
\hline B. cereus & $-43.67 \pm 18.3$ & $-81.7 \pm 22.2$ & $-28.9 \pm 22.8$ & $-85.3 \pm 3.4$ \\
L. monocytogenes & $-51.04 \pm 26.1$ & $-93 \pm 30.4$ & $-30.1 \pm 25.6$ & $-102.5 \pm 30.1$ \\
S. aureus & $-220.24 \pm 51.9$ & $-209.2 \pm 88.8$ & $-192.3 \pm 53$ & $-377.1 \pm 16.2$ \\
C. albicans & $-1.8 \pm 9.7$ & $-1.1 \pm 12.5$ & $22.6 \pm 7.2$ & $-43.9 \pm 7.7$ \\
Scerevisiae & $-8.6 \pm 7.2$ & $-4.1 \pm 9.3$ & $16.9 \pm 9.4$ & $-14.1 \pm 5.4$ \\
C tropicalis & $-32.4 \pm 17.1$ & $-30.8 \pm 13.4$ & $-11.7 \pm 5.5$ & $-46.8 \pm 2.8$ \\
A. niger & $-19.7 \pm 16.6$ & $-41.9 \pm 5.3$ & $-23.2 \pm 3.3$ & $5.3 \pm 15$ \\
F. oxysporum & $-32.2 \pm 9.9$ & $-26.6 \pm 6.4$ & $-33.6 \pm 7.3$ & $-11 \pm 5.5$ \\
P. expansum & $-129.5 \pm 19.5$ & $-146.9 \pm 7.3$ & $-96.2 \pm 10.7$ & $-33.9 \pm 2.9$ \\
\hline
\end{tabular}

FFB: Flour fish broth, FOB: Forage oats broth, CWB: Cheese whey broth.

Table 5. Performance of the strain L. mesenteroides PIM5 in FFB and MRS broth.

\begin{tabular}{lcccc}
\hline \multirow{2}{*}{ Variable } & \multicolumn{2}{c}{ FFB } & MRS \\
\cline { 2 - 5 } & Sterile broth & CFS & Sterile broth & CFS \\
\hline pH & $6.2 \pm 0.00$ & $4.35 \pm 0.03$ & $6.52 \pm 0.00$ & $4.38 \pm 0.00$ \\
Titratable acidity g/100 ml & $0.09 \pm 0.00^{*}$ & $0.80 \pm 0.01^{* *}$ & $0.22 \pm 0.01^{* * *}$ & $0.79 \pm 0.02^{* *}$ \\
Proteins g/l & $2.17 \pm 0.00$ & $0.49 \pm 0.06$ & $0.56 \pm 0.00$ & $0.27 \pm 0.01$ \\
Reducing sugars g/l & $19.01 \pm 0.18$ & $8.35 \pm 0.19$ & $18.90 \pm 1.09$ & $13.12 \pm 0.68$ \\
\hline
\end{tabular}

${ }^{\star} \mathrm{g}$ of malic acid. ${ }^{* *} \mathrm{~g}$ of lactic acid, ${ }^{* * *} \mathrm{~g}$ of acetic acid

However, L. mesenteroides PIM5 displayed the best antimicrobial profile since it could inhibit at least four indicator microorganisms in each culture media employed.

The antimicrobial activity of LAB-CFS, when grown in media formulated with agroindustrial wastes against indicator microorganisms, is incorporated in Table 1 of Supplementary Information (TS1). The CFS's antimicrobial activity from LAB was significantly affected $(p<0.05)$ by the culture media and the LAB strain.

The CFS of $L$. mesenteroides PIM5 grown in FOB was the only CFS able to moderately inhibit the growth $(p<$ 0.05 ) of more than two indicator microorganisms (B. cereus $35.5 \% \pm 4.5$, L. monocytogenes $46.7 \% \pm 8.6$, C. albicans $39 \% \pm 5.5$, S. cerevisiae $45.2 \% \pm 14.9$ and C. tropicalis $49.2 \% \pm 15.1)$. Regarding the antimicrobial activities of the CFS from LAB grown in the CWB, L. mesenteroides PIM5 CFS moderately inhibited the growth $(p<0.05)$ of five indicator microorganisms (B. cereus $39.5 \% \pm 6.6, \mathrm{~L}$. monocytogenes $45.9 \% \pm 4.3$, C. albicans $34.4 \% \pm 7.7$, S. cerevisiae $43.1 \% \pm 11.5$ and F. oxysporum $23.3 \% \pm 3.7$ ). Moreover, the CFS of the strains E. faecium PIM4, E. mundtii TOV9 and L. mesenteroides PEP12 presented moderate inhibition $(p<0.05)$ against B. cereus and the yeasts evaluated. About the FFB, the CFS of the strain L. mesenteroides CAL14 completely inhibited the growth ( $p$ $<0.05)$ of L. monocytogenes $(114.2 \% \pm 53.5)$ and strongly inhibited the growth of B. cereus $(91.1 \% \pm 20.6)$, C. albicans $(74.6 \% \pm 2.6)$, S. cerevisiae $(80.4 \% \pm 6.7)$ and C. tropicalis $(62.8 \% \pm 3.4)$. Furthermore, the CFS of L. mesenteroides PIM5 moderately inhibited the growth $(p<0.05)$ of L. monocytogenes $(27.9 \% \pm 21)$, C. albicans ( $39 \% \pm 5.5)$, S. cerevisiae ( $45.2 \% \pm 14.9)$, and C. tropicalis $(49.2 \% \pm 15.1)$. When the LAB employed were cultured in MRS broth, the strain L. mesenteroides CAL14 reduced the growth $(p<0.05)$ of yeast $(C$. albicans $47.3 \% \pm 7$, S. cerevisiae $16.4 \% \pm 6.1$, C. tropicalis $20.7 \% \pm 10.9$ ) and molds (A. niger $58.3 \% \pm 5$, F. oxysporum $22.2 \% \pm 16.7$, P. expansum $33.4 \% \pm 17.9$ ). Likewise, E. mundtii ELO8 and L. mesenteroides PIM5 were able to inhibit moderately the growth $(p<0.05)$ of L. monocytogenes, S. cerevisiae, and molds.

Antimicrobial activities of sterile culture media formulated with agroindustrial wastes and MRS broth against indicator microorganisms (Table 4) demonstrated that the MRS broth and none of the broths formulated with agroindustrial wastes exerted antimicrobial activity except for the CWB, which inhibited the growth of C. albicans $(22.6 \% \pm 7.2)$ and S. cerevisiae $(16.9 \% \pm 9.4)$.

\section{Chemical Analysis}

The chemical analysis of the CFS of L. mesenteroides PIM5 grown in FFB and MRS is shown in Table 5. The values for $\mathrm{pH}$ and lactic acid production were similar in both CFS. However, protein consumption and the concentration of reducing sugars were higher in FFB than in MRS broth. Less than a quarter of the initial proteins present in FFB remained in the CFS, whereas less than half of the MRS broth proteins remained in its CFS. Regarding the uptake of the reducing sugars, more than half was consumed in FFB, while in MRS, only over a third of the reducing sugar content was consumed. The results demonstrate the differences in components consumption in both formulations.

\section{Discussion}

Culture media equivalent to MRS broth were formulated substituting carbon, nitrogen, and peptone sources with agroindustrial waste to assess the influence of the components on the antimicrobial activity of LAB CFS. A base culture medium was formulated, adding apple bagasse $(\mathrm{AB})$ instead of glucose as a carbon source and yeast water waste (YW) instead of yeast extract as a nitrogen, amino acid, and vitamin source. Inorganic salts were 
added in the same concentration as in the MRS broth original formulation. Three culture media were formulated, adding different protein sources (fish flour, forage oats, and whey) to substitute for peptone and meat extract. Each source was added in equivalent quantities as for the nitrogen provided by peptone and meat extract. All the agroindustrial wastes employed have already been evaluated as substrates for lactic acid fermentation. LAB successfully fermented apple bagasse for lactic acid production [18], brewer's yeast wastes for protease production [4], forage oats for silage [26], hydrolyzed fish viscera as a growth substrate [27], and whey for bacteriocin production [1].

$\mathrm{AB}$ was revealed to be a good carbon source for lactic acid fermentation; according to the chemical analysis, it contains an elevated concentration of simple sugars, as determined by the reducing sugar concentration. The percentage of available sugars will depend on the fruit variety and the method employed for juice preparation [28]. However, the content of reducing sugars in $\mathrm{AB}$ (62.41\%) was close (68\%) to that reported by Gullón et al. [18]. Based on this concentration, the amount of $\mathrm{AB}$ added to the formulated medium was equal to that supplied by the glucose incorporated into the MRS broth $(8 \mathrm{~g} \mathrm{C} / \mathrm{L})$. Fructose is the major component of the sugars contained in $\mathrm{AB}$ [18]. When this sugar is present in a culture medium, L. mesenteroides can employ a portion as an electron acceptor to reduce fructose to mannitol, thus acquiring energy. Another portion is transformed to lactic and acetic acid and even to small amounts of ethanol [20].

Moreover, a strain of Lactobacillus amylovorus showed the same growth rate with a mixture of glucose and fructose than when glucose was used as the only carbon source [20]. Besides, LAB can transform oligosaccharides into single sugars that can be efficiently absorbed. For instance, LAB strains can obtain fructose from the fructans present in apple bagasse [29]. Therefore, a sugar mix ingredient like AB would sustain LAB growth. Although proteins are also a constituent of $\mathrm{AB}$, their content is low [28], as confirmed in this report.

The protein content of YW from beer production was lower than previously reported by dos Santos Mathias et al. [19]. Yeast extract is a good source of nitrogen and carbon; nevertheless, its percentages would change according to their physiological state and growth phase [28]. Still, the amount of nitrogen and carbon provided by YW was calculated to add an amount equivalent to that provided by the commercial yeast extract used in the MRS broth. Yeast waste is rich in soluble proteins due to yeast's autolysis at the end of fermentation and sterilization [19]. It is also a good source of amino acids (lysine, leucine, isoleucine, and tryptophan), B vitamins, purine and pyrimidine bases, and minerals that influence the growth of LAB during lactic acid fermentation $[7,11,19]$. Yeast waste from the brewing industry has already been proved to cause an increase in LAB biomass, a reduction in fermentation time [28], and complete depletion of glucose and fructose [18].

Furthermore, yeast water waste from beer production has a low $\mathrm{C} / \mathrm{N}$ ratio due to its high carbon content, which enhances biomass production; therefore, it has high potential for being used as an ingredient in fermentation culture media [19]. FO nitrogen content was similar to previous reports $[26,30]$. FO is a suitable substrate for lactic acid fermentation since there are several LAB isolated from this substrate. It contains a good proportion of proteins, carbohydrates, and minerals to support LAB growth [26,30]. Similarly, whey has a significant amount of proteins, lipids, vitamins, and minerals, in addition to lactose [5] available for LAB growth. However, the nitrogen content of $\mathrm{CW}$ was lower than the nitrogen provided by peptone and meat extract in the MRS broth. Thus, the broth was prepared by adding all the ingredients to the CW without adding extra water. The total protein of FF (24.91 $\mathrm{g} / \mathrm{l}$ ) was lower than that reported by Vázquez et al. [3] for fish wastes ( 31.3 to $43 \mathrm{~g} / \mathrm{l}$ ). Nonetheless, the nitrogen content provided by FF and added to the FFB was calculated to add an equal amount to that supplied by peptone and meat extract in MRS formulation.

Although the nitrogen provided by agroindustrial wastes as protein sources was equal to the amount provided by the MRS broth, the C/N ratio was lower in the formulated media than in the MRS broth due to a lower carbon content in these agroindustrial sources than that supplied by peptone and meat extract in the MRS broth. The C/N ratio is a key characteristic for culture media to accomplish sufficient growth and lactic acid fermentation. Carbon sources are used in LAB cells for energy production, while nitrogen, vitamins, and minerals produce biomass, lactic acid, and cell maintenance $[7,13]$. A culture medium with a high $\mathrm{C} / \mathrm{N}$ ratio would help produce bioactive metabolites from proteolytic LAB [19].

Agroindustrial wastes employed as protein sources favored LAB's antimicrobial activity, but it varies according to the protein source supplied and the LAB strain. The method used for the evaluation of antimicrobial activity was selected based on our previous results. The buffered broth was able to neutralize the lactic acid present in the CFS. The method can detect a reduction in the microbial growth even when the inhibition is not complete; therefore, it was possible to assess differences that could not be observed with other methods such as the spot-onthe-lawn or the determination of minimal inhibitory or bactericidal concentrations. The method also allowed us to test the CFS against more indicator microorganisms, including fungi, yeast, and bacteria [22].

The antimicrobial activity might be due to the production of antimicrobial peptides released from the FF by proteases of LAB since the media's $\mathrm{pH}$ was buffered to avoid the action of acids produced by LAB [14], and all these LAB were shown to be proteolytic strains [22]. These results are similar to Ruthu et al. [14], who also reported the inhibition of $B$. cereus and L. monocytogenes by a protein hydrolysate obtained from fish wastes fermented by LAB. Antimicrobial peptides can be obtained at a lower cost by enzymatic hydrolysis by employing LAB proteolytic activity [16]. Liu et al. [31] report that the LAB proteolytic system comprises cell-wall bound proteinase hydrolyzing protein into oligopeptides, peptide transporters in charge of transferring the peptides to the cell, and intracellular peptidases in charge of degrading the transferred peptides into smaller peptides and amino acids. Furthermore, protein breakdown is favored by lactic acid production since it disturbs protein structure, enhancing protease activity [32]. Besides the production of antimicrobial peptides by LAB, bacteriocins production is another possibility. A strain of Lactobacillus plantarum produced bacteriocins from a medium 
supplemented with whey [1]. Pediococcus acidilactici produced pediocin from fish wastes hydrolysates [3]. Strains of L. mesenteroides [33, 34], Enterococcus mundtii and Enterococcus faecium [35] have also been reported as bacteriocin producers.

Whey components are mainly lactose and whey proteins; they also consist of amino acids, vitamins, and salts of calcium, potassium, sodium, and magnesium $[6,17]$. Besides lactose fermentation capacity, LAB proteolytic systems can release antimicrobial peptides from proteins provided by whey $[16,36]$ like casein, $\beta$-lactoglobulin, $\alpha$ lactalbumin, and serum albumin. Therefore, whey is suitable for LAB growth and production of antimicrobial peptides [1]. For instance, Theolier et al. [36] were able to identify fractions of $\beta$-lactoglobulin and $\alpha$-lactalbumin with antimicrobial activity after hydrolyzing whey. However, lactoferrin, lactoperoxidase, and lysozyme present in whey have been shown to exert antimicrobial activities $[8,36]$. This observation was confirmed when $C$. albicans and S. cerevisiae were incubated with sterilized CWB, and their growth was partially inhibited. Therefore, the partial inhibition of C. albicans and S. cerevisiae when grown in sterilized CWB can result from antimicrobial whey proteins. Another possibility is that proteins are partially hydrolyzed during cheese production [36], which opens the probability that antimicrobial peptides present in the whey could have exerted such inhibition of yeasts. Similarly, peptides with antimicrobial activity against yeasts could be released during sterilization of the CWB, remaining in the sterilized medium.

Phenolic compounds present in apple bagasse do not affect Leuconostoc spp. since they can survive in plants due to their tolerance to high amounts of phenolic compounds which they can metabolize, producing metabolites with less antimicrobial activity [29].

In the present research, lactic acid production in the FFB and MRS was similar, as previously reported for a fructose-containing medium [12]. However, a better nutrient uptake was determined for L. mesenteroides when fructose was present in the medium [33], which explains the preferential consumption of protein and reducing sugars in FFB compared to MRS broth. The uptake of nutrients in the culture media formulated with agroindustrial wastes would produce an expended medium with less organic load reducing the biological oxygen demand [17].

Culture media formulated with agroindustrial wastes proved to positively influence the antimicrobial activity of $\mathrm{LAB}$ isolated from fresh vegetable sources. The fish flour broth was the medium that most encouraged the antimicrobial activity of most of the LAB strains evaluated. However, antimicrobial activity is a strain-dependent feature, and therefore, production and characterization of antimicrobial peptides by Leuconostoc mesenteroides PIM5 must be further investigated since this strain presented the best antimicrobial profiles against the indicator microorganisms assayed in the three media formulated.

\section{Acknowledgments}

Linares Morales. J. R. is a Research Fellow from the Consejo Nacional de Ciencia y Tecnología (Mexico) during his Ph.D. studies (Fellowship No. 618820).

\section{Conflict of Interest}

The authors have no financial conflicts of interest to declare.

\section{References}

1. Sabo SS, Converti A, Ichiwaki S, Oliveira RPS. 2019. Bacteriocin production by Lactobacillus plantarum ST16Pa in supplemented whey powder formulations. J. Dairy Sci. 102: 87-99.

2. Food and Agriculture Organization of the United Nations. 2016. The state of world fisheries and aquaculture. Contributing to food security and nutrition for all http://www.fao.org/3/a-i5555e.pdf. Accessed Oct. 10, 2020.

3. Vázquez JA, Meduíña A, Durán AI, Nogueira M, Fernández-Compás A, Pérez-Martín RI, et al. 2019. Production of valuable compounds and bioactive metabolites from by-products of fish discards using chemical processing, enzymatic hydrolysis, and bacterial fermentation. Mar. Drugs 17: 139.

4. Mathias TR, de Aguiar PF, Silva JB, de Mello PPM, Sérvulo EFC. 2017. Brewery wastes reuse for protease production by lactic acid bacteria fermentation. Food Technol. Biotechnol. 55: 218-224.

5. Boumaiza MA, Colarusso E, Parrilli E, Garcia-Fruitós A, Casillo A, Arís MM, Corsaro D, et al. 2018. Getting value from the waste: recombinant production of a sweet protein by Lactococcus lactis grown on cheese whey. Microb. Cell Fact. 17: 1-9.

6. Ryan MP, Walsh G. 2016. The biotechnological potential of whey. Rev. Environ. Sci. Biotechnol. 15: 479-498.

7. Veeravalli SS, Mathews AP. 2018. Exploitation of acid-tolerant microbial species for the utilization of low-cost whey in the production of acetic acid and propylene glycol. Appl. Microbiol. Biotechnol. 102: 8023-8033.

8. Chalermthai B, Chan WY, Bastidas-Oyanedel JR, Taher H, Olsen BD, Schmidt JE. 2019. Preparation and characterization of whey protein-based polymers produced from residual dairy streams. Polymers (Basel) 11: 1-11.

9. Bolarinwa IF, Orfila C, Morgan MRA. 2015. Determination of amygdalin in apple seeds, fresh apples and processed apple juices. Food Chem. 170: 437-442.

10. Bravo S, Morales M, del Mónaco SM, Caballero AC. 2019. Apple bagasse as a substrate for the propagation of Patagonian wine yeast biomass. J. Appl. Microbiol. 126: 1414-1425.

11. Bustos G, Moldes AB, Cruz JM, Domínguez JM. 2004. Formulation of low-cost fermentative media for lactic acid production with Lactobacillus rhamnosus using vinification lees as nutrients. J. Agric. Food Chem. 52: 801-808.

12. Pessione A, Zapponi M, Mandili G, Fattori P, Mangiapane E, Mazzoli R, et al. 2014. Enantioselective lactic acid production by an Enterococcus faecium strain showing potential in agro-industrial waste bioconversion: physiological and proteomic studies. J. Biotechnol. 173: 31-40.

13. Wang Y, Tashiro Y, Sonomoto K. 2015. Fermentative production of lactic acid from renewable materials: recent achievements, prospects, and limits. J. Biosci. Bioeng. 119: 10-18.

14. Ruthu, Murthy PS, Rai AK, Bhaskar N. 2014 Fermentative recovery of lipids and proteins from freshwater fish head waste with reference to antimicrobial and antioxidant properties of protein hydrolysate. J. Food Sci. Technol. 51: 1884-1892. 
15. Bartkiene E, Lele V, Sakiene V, Zavistanaviciute P, Ruzauskas M, Bernatoniene J, et al. 2019. Improvement of the antimicrobial activity of lactic acid bacteria in combination with berries/fruits and dairy industry by-products. J. Sci. Food Agric. 99: 3992-4002.

16. Worsztynowicz P, Białas W, Grajek W. 2020. Integrated approach for obtaining bioactive peptides from whey proteins hydrolysed using a new proteolytic lactic acid bacteria. Food Chem. 312: 126035.

17. Kasmi M, Hamdi M, Trabelsi L. 2017. Processed milk waste recycling via thermal pretreatment and lactic acid bacteria fermentation. Environ. Sci. Pollut. Res. 24: 13604-13613.

18. Gullón B, Yáñez R, Alonso JL, Parajó JC. 2008. 1-Lactic acid production from apple pomace by sequential hydrolysis and fermentation. Bioresour. Technol. 99: 308-319.

19. dos Santos Mathias TR, Alexandre VMF, Cammarota MC, de Mello PPM, Sérvulo EFC. 2015. Characterization and determination of brewer's solid wastes composition. J. Inst. Brew. 121: 400-404.

20. Leroy F, De Winter T, Adriany T, Neysens P, De Vuyst L. 2006. Sugars relevant for sourdough fermentation stimulate growth of and bacteriocin production by Lactobacillus amylovorus DCE 471. Int. J. Food Microbiol. 112: 102-111.

21. Castillo-Castillo Y, Ruiz-Barrera O, Burrola-Barraza ME, Marrero-Rodriguez Y, Salinas-Chavira J, Angulo-Montoya C, et al. 2016. Isolation and characterization of yeasts from fermented apple bagasse as additives for ruminant feeding. Brazilian J. Microbiol. 47: 889-895.

22. Linares-Morales JR, Cuellar-Nevárez GE, Rivera-Chavira BE, Gutiérrez-Méndez N, Pérez-Vega SB, Nevárez-Moorillón GV. 2020. Selection of lactic acid bacteria isolated from fresh fruits and vegetables based on their antimicrobial and enzymatic activities. Foods 9: 1399.

23. Association of Official Analytical Chemists, Official Methods of Analysis. $200017^{\text {th }}$ Ed., AOAC International, Gaithersburg, MD.

24. Miller G. 1959. Use of dinitrosalicylic acid reagent for determination of reducing sugar. Anal. Chem. 31: 426-428.

25. Bradford MM. 1976. A rapid and sensitive method for the quantitation of microgram quantities of protein utilizing the principle of protein-dye binding. Anal. Biochem. 72: 248-254.

26. Zhang M, Wang X, Cui M, Wang Y, Jiao Z, Tan Z. 2018. Ensilage of oats and wheatgrass under natural alpine climatic conditions by indigenous lactic acid bacteria species isolated from high-cold areas. PLoS One 13: e0192368.

27. Vázquez JA, González MP, Murado MA. 2004. Peptones from autohydrolysed fish viscera for nisin and pediocin production. J. Biotechnol. 112: 299-311.

28. Mamma D, Topakas E, Vafiadi C, Christakopoulos P. 2009. Biotechnological Potential of Fruit Processing Industry Residues. In Singh nee' Nigam P, Pandey A. (eds) Biotechnology for Agro-Industrial Residues Utilisation. Springer, Dordrecht.

29. Filannino P, Di Cagno R, Gobbetti M. 2018. Metabolic and functional paths of lactic acid bacteria in plant foods: get out of the labyrinth. Curr. Opin. Biotechnol. 49: 64-72.

30. Kafilzadeh F, Heidary N. 2013. Chemical composition, in vitro digestibility and kinetics of fermentation of whole-crop forage from 18 different varieties of oat (Avena sativa L.). J. Appl. Anim. Res. 41: 61-68.

31. Liu M, Bayjanov JR, Renckens B, Nauta A, Siezen RJ. 2010. The proteolytic system of lactic acid bacteria revisited?: a genomic comparison. BMC Genomics 11:36.

32. Nediani M, García L, Saavedra L, Martínez S, López Alzogaray S, Fadda S. 2017. Adding value to goat meat: biochemical and technological characterization of autochthonous lactic acid bacteria to achieve high-quality fermented sausages. Microorganisms 5: 26 .

33. Metsoviti M, Paramithiotis S, Drosinos EH, Skandamis PN, Galiotou-Panayotou M, Papanikolaou S. 2011. Biotechnological valorization of low-cost sugar-based media for bacteriocin production by Leuconostoc mesenteroides E131. N. Biotechnol. 28: 600-609.

34. Wulijideligen, Asahina T, Hara K, Arakawa K, Nakano H, Miyamoto T. 2012. Production of bacteriocin by Leuconostoc mesenteroides 406 isolated from Mongolian fermented mare's milk, airag. Anim. Sci. J. 83: 704-711.

35. Vera Pingitore E, Todorov SD, Sesma F, Gombossy de Melo Franco BD. 2012. Application of bacteriocinogenic Enterococcus mundtii CRL35 and Enterococcus faecium ST88Ch in the control of Listeria monocytogenes in fresh Minas cheese. Food Microbiol. 32: 38-47.

36. Théolier J, Hammami R, Labelle P, Fliss I, Jean J. 2013. Isolation and identification of antimicrobial peptides derived by peptic cleavage of whey protein isolate. J. Funct. Foods 5: 706-714. 